\title{
Microstructural Characterization of Casein by Microscopy and Spectroscopy Techniques
}

Liliana Edith Rojas-Candelas ${ }^{1}$, José Jorge Chanona-Pérez ${ }^{1}$, Juan Vicente Méndez Méndez ${ }^{2}$, Claudia Albany Resendiz-Mora ${ }^{1}$, Héctor A. Calderón-Benavides ${ }^{3}$ and Felipe Cervantes-Sodi ${ }^{4}$

1. Escuela Nacional de Ciencias Biológicas/Instituto Politécnico Nacional,

2. Centro de Nanociencias y Micro y Nanotecnologías/ Instituto Politécnico, Nacional Ciudad de México, México.

3. Escuela Superior de Física y Matemáticas/ Instituto Politécnico Nacional, Ciudad de México, México.

4. Departamento de Física y Matemáticas/ Universidad Iberoamericana, Ciudad de México, México.

The study of the structure and mechanical properties of Caseins at nanoscale is an interesting topic to food nanotechnology [1,2,3]. The aim of this work was to study of the microstructure of Casein by SEM (scanning electron microscopy), CRYO-TEM (Cryogenic transmission microscopy), AFM (atomic force microscopy) and Raman spectroscopy. Overall morphology and topography of Casein were studied by SEM (Hitachi, SU3500 I), CRYO-TEM (JEOL COM, USA) and AFM (Bruker, Bioscope Catalyts ScanAsyst, USA). Whereas the secondary structure of Casein was studied by Raman spectroscopy (confocal Raman microscope, USA).

Fig. 1 shows SEM images of powder protein, where the Casein is like amorphous agglomerates, these morphologies correspond to its obtention process crystallization. Fig 2. Shows CRYO-TEM Casein micelle diameter was $122.60 \pm 63.40 \mathrm{~nm}$. Also by means of AFM, the average roughness of the Casein at their isoelectric point and diluted in phosphate buffer solution (Fig. 3), its isoelectric point (5.0) and at $\pm 1 \mathrm{pH}$ unit, $\mathrm{Ra}$ (arithmetic roughness) was obtained from scanning area of $5 \times 5 \mu \mathrm{m}$. At pH $5 \mathrm{Ra}$ for Casein was $8.023 \pm 5.28 \mathrm{~nm}$, while that at $\mathrm{pH} 4$ was $1.56 \pm 0.58 \mathrm{~nm}$ and $\mathrm{pH} 6$ was $2.59 \pm 0.84 \mathrm{~nm}$. Thus the protein in its isoelectric point showed a largest Ra values due to the agglomeration of proteins. Then parameters related to secondary structure of Casein proteins were determined by FT-Raman Spectroscopy according to [4]. Fig 4 shows spectrum of protein, where the amide 1 (Fig 4a) and amide 2 (Fig 4b) bands for the Casein presented $7.90 \%$ of the low frequency component in the laminar $\beta$ arrangement and $6.02 \%$ of the high frequency component in the laminar $\beta$ arrangement, while for the rotation and $\alpha$ helix arrangement it was of $22.59 \%$ and $63.42 \%$ respectively.

This preliminary study of morphology and topography of Casein by microscopy techniques provided an initial overview to establishing the dispersion conditions and $\mathrm{pH}$ 's to study its mechanical properties by nanoindentation with AFM.

\section{References:}

[1] S Gaspard et al., International Dairy Journal. 73 (2017), p. 98.

[2] A Ansari, Nanoparticles: Properties, Classification, Characterization, and Fabrication. (2010), p. 122.

[3] S Yazdi, M Corredig and D Dalgleish, Food hydrocolloids. 42 (2014), p. 171.

[4] M Carbonaro and A Nucara, Amino Acids. 38 (2010), p. 679. 


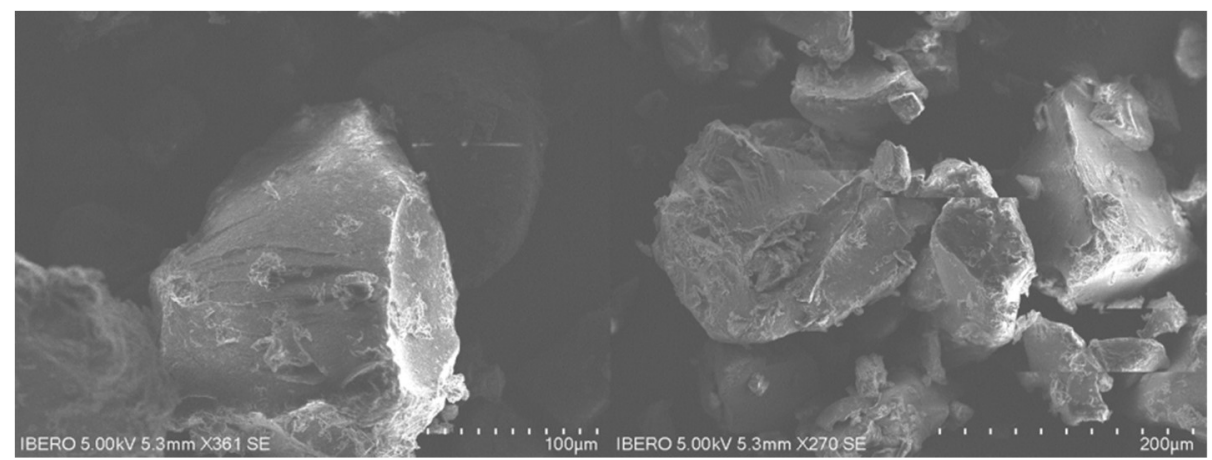

Figure 1. Scanning electron microscopy image of powder Casein.

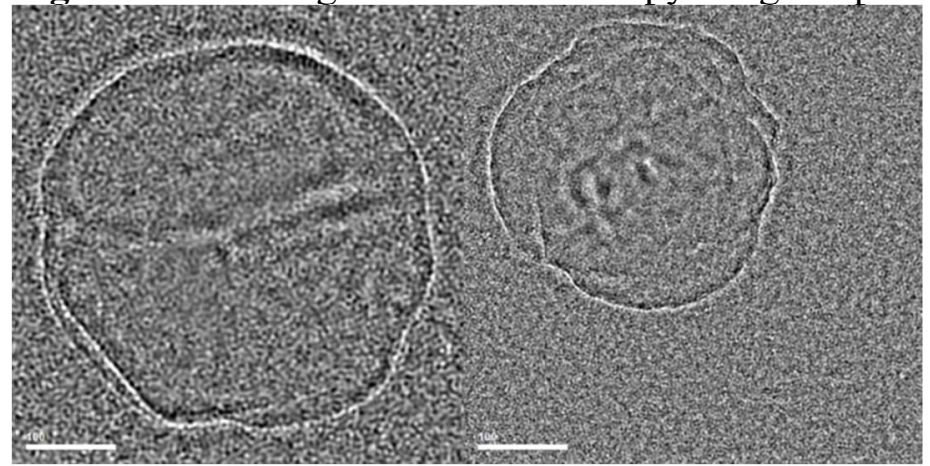

Figure 2. Cryo-transmission electron microscope images of Casein micelles. Bar corresponds to 100 $\mathrm{nm}$
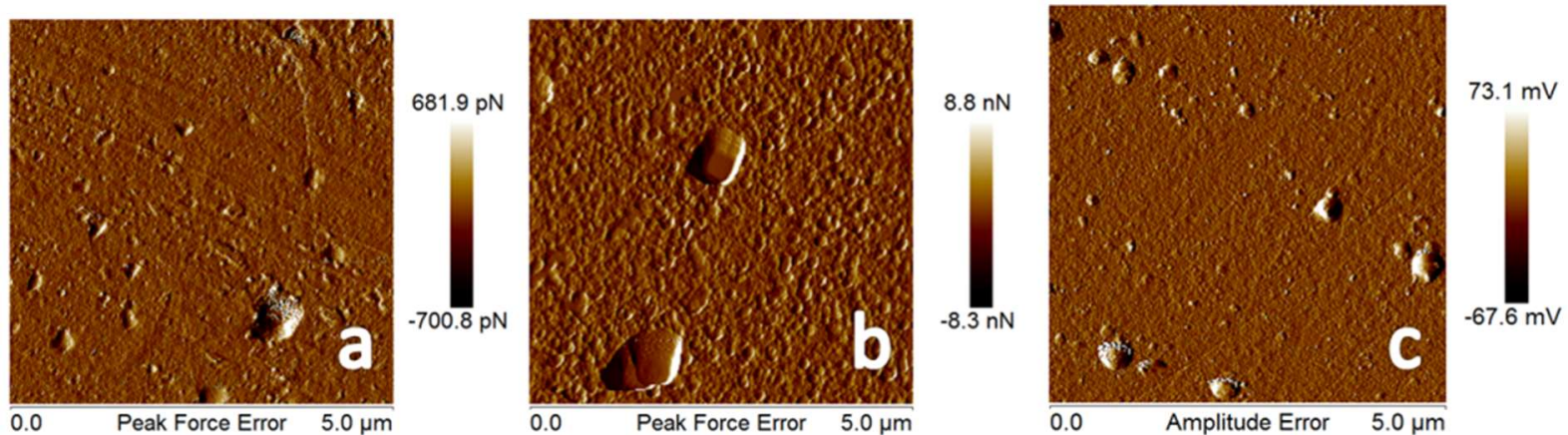

Figure 3. AFM images Casein a) $\mathrm{pH} 4$, b) $\mathrm{pH} 5$ and c) $\mathrm{pH} 6$
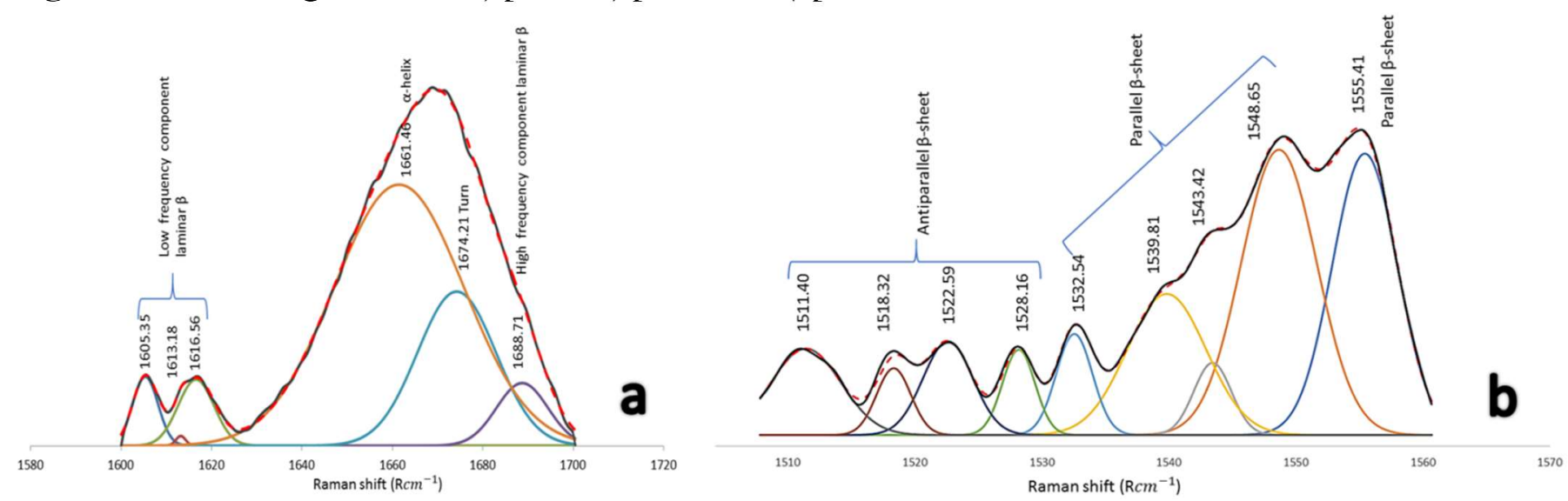

Figure 4. a) Amide I band and b) Amide II band of Casein powder. 